\title{
Modernizing African Townships using TV White Space Networks: A Case study of Mankweng Township in South Africa
}

\author{
Tlou M. Ramoroka ${ }^{1, *}$, Moshe T. Masonta ${ }^{2}$ and Adrian Kliks ${ }^{3}$ \\ ${ }^{1}$ TV White Spaces Centre, University of Limpopo, Polokwane, South Africa \\ ${ }^{2}$ Council for Scientific and Industrial Research (CSIR), Meraka Institute, Pretoria, South Africa \\ ${ }^{3}$ Faculty of Electronics and Telecommunications, Poznan University of Technology, Poznan, Poland
}

\begin{abstract}
The role of cheap and easy access to various telecommunication facilities is crucial for further community development. Such an observation is of particular importance for the developing countries all over the world since reliable and open access to communication systems can fasten the reduction of the development gap. In this work we analyse the benefits that can be obtained by application of TV White Space network, i.e. the network that operates in vacated TV band in a cognitive manner. The whole analysis is conducted based on specific use-case, i.e. the test network deployed in the Mankweng Township
\end{abstract}

Keywords: e-Learning, e-Surveillance, e-community, broadband internet access, developing countries, Mankweng Township, TV white spaces.

Received on 28 January, 2016, accepted on 14 May, 2016, published on 18 May, 2016

Copyright (C) Tlou M. Ramoroka et al., licensed to EAI. This is an open access article distributed under the terms of the Creative Commons Attribution licence (http://creativecommons.org/licenses/by/3.0/), which permits unlimited use, distribution and reproduction in any medium so long as the original work is properly cited.

doi: 10.4108/eai.18-5-2016.151252

\section{Introduction}

Recently, both developed and developing countries are experiencing unprecedented high urbanization rates due to 'modern community development' and high standard services provided in building smart town and cities through knowledge economy [1], [2]. Urban areas, mostly aspired smart towns and cities, have become places suitable for making a living as they effectively provide people with the services they want and need as compared to townships and rural areas [1],[2], [3], [4]. As a result, the majority of people in developing countries reside in urban areas in search of quality life. At the same time policy development to curb urbanization and the decentralization of development to rural areas and townships has also attracted attention in many countries [3]. The latter is more focused, among others, on: a)

*Corresponding author. millicent.ramoroka@ul.ac.za economic restructuring, b) rural industrialization, c) improved environmental and energy planning, d) easy accessibility of public services and infrastructure, and e) innovative Information and Communication Technologies (ICT) in townships and rural areas. In South Africa, high rates of rural-urban migration are a result of limited or lack of services and infrastructures in most rural areas and townships [4]. Although urban areas are associated with modern knowledge economy, they also have adverse effects such as congestion, environmental pollution and degradation, and high rates of crime, among others [2].

The decentralization of development from urban areas to townships and rural areas has been the most effective strategy in dealing with inequalities that exist between these areas [3]. Thus, bringing services and infrastructure that are key to knowledge economy development especially associated with smart towns and cities close to people in townships and rural areas is of importance in 
this regard. For the purpose of this paper, attention will be given to the decentralization of ICT through low cost Internet connectivity in order to achieve modern development in South Africa's townships. The paper argues that if people in townships are well connected through low cost Internet such as the TV White Space Networks (TVWSN), they will reduce the high rates of urbanization and mostly contribute to modern community development $[5,6]$. The goal and originality of this paper stake out on the discussion about the idea of community development due to the deployment of TVWSN. Intentionally, the main attention is paid on the Mankweng Township as an example of developing region. Although we focus on the specific case, the conclusions drawn from this work can be easily projected to townships in other regions. Thus, in order to prove the practicality of this concept we will discuss intentionally the real implementation of TVWSN in the abovementioned scenario, i.e. Mankweng Township in the Limpopo Province in South Africa. Three use-cases will be discussed: delivery of broadband Internet for e-Learning, application of TVWSN for smart metering and eSurveillance. This paper is an extension of the previous work of the authors [7].

The remainder of this paper is organized as follows: Section 2 provides the motivation for this study. Section 3 discusses the technical, legal and economical enablers for real implementation of TVWSN. Section 4 presents how TVWSN can fasten the development of specific economy branches and in consequence of the certain region. Finally section 5 concludes this paper.

\section{Modern Community Development and TVWSNs}

Urban development is characterized by a number of components which include economic development; environmental, built environment and energy; public services and infrastructure; urban food production, urban renewal; and, transport and communication development, among others [1, 2, 3, 4]. These components rely on each other and work as a system in building towns and cities that are sustainable and further fulfil people's economic, environmental and social needs. In economic development, fulfilling the expectations of urban dwellers with regard to local economic development is of importance. Urban areas are also expected to function as economic engines for surrounding areas. Although economic development leads to increases in Gross Domestic Product (GDP), it also leads to adverse structural changes [4]. For example, in South Africa the rural agricultural sector declines as a result of loss of the labour force due to urbanization while the majority of the same labour force remains either under-employed or unemployed in urban areas.

Environmental and energy development planning and management is very crucial especially to achieve sustainable development related to the built environment which include infrastructure such as buildings and roads, among others $[3,5,6]$. In South Africa, the use of energy in urban areas is also at stake due to population growth. Whereas the majority of people, institutions and businesses heavily rely on electricity as their main source of energy [5], alternative renewable sources such as solar and wind are rarely used to generate energy. Thus, the environment and energy must be used efficiently in order to achieve sustainable modern urban development which is mostly measured by the built environment among other measures. The natural environment of communities is very important in defining good towns and cities.

Easy accessibility to basic public services such as water, electricity, health, education, transport and infrastructures associated with these services is one of the reasons for migration [8, 9]. Of late, attention is on transforming the existing urban areas into smart towns and cities [1, 2, 3, 4, 5] rather improving services and infrastructure such as water, electricity and roads which are mostly decentralized to townships and rural areas and are easy to extend in urban area. The needs of most urban migrants are revolve around access to ICT and its related infrastructure which is underlying the move towards smart towns and cities and knowledge economy [2, 3, 4]. In order to build smart towns and cities, emphasis is on improving communication channels through the adoption of affordable ICT, among other dimensions. Similarly to other services and infrastructures, it becomes significant that ICT related infrastructures and services be decentralized to townships and rural areas to avoid high population rates in urban areas $[4,5]$.

To assist in the facilitation of the decentralization of some of the services, South Africa's ICT development is governed by a number of legislatives which include National Development Plan (NDP) 2030; 2013 ICT Research, Development and Innovation (RDI) Roadmap; and, 2013 SA Connect: Creating Opportunities, ensuring inclusion policy. This legislative framework is working towards ensuring that all South Africans have access to effective ICT infrastructure which is necessary for their personal development and that of the nation regardless of their socio-economic status. The NDP 2030 recognizes ICT as one of the key infrastructures for economic, social and environmental development. Accordingly, the plan states that "by 2030 ICT will underpin the development of a dynamic and connected information society and a vibrant knowledge economy that is more inclusive and prosperous" [10]. Additionally, ICT will be used as a tool to reduce spatial exclusions through the involvement and participation of all South Africans. In responding to the NDP 2030, the 2013 ICT RDI Roadmap seeks to "overcome the digital divide by leveraging advances in ICT to address socioeconomic challenges [11]. Whereas the 2013 SA Connect policy outlines "a vision and longterm strategy that can be immediately instituted, to catalyse broadband connectivity in South Africa, with the objective of creating a dynamic high-speed information 
infrastructure to meet the needs of the South African citizens in a modern economy and information society" [12]. In order to achieve this vision, improved access to ICT infrastructure especially through the application of the TVWSNs in townships and rural areas is of importance.

The application of TVWSNs for further community development is currently considered all over the world; however in this paper it is intentionally analysed in the context of developing regions, treating the Mankweng Township in South Africa as an arbitrarily selected representative. As it will be discussed later, TVWSN can be a beneficial solution for reduction of ICT gap in developing regions since it offers affordable Internet. In particular, utilization of TV band guarantees high signal coverage with the usage of relatively low power compared to higher frequency bands (OPEX reduction). Moreover, as the amount of white spaces (licensed, but unused frequency gaps) in developing countries is rather high, wider spectrum bands can be assigned for opportunistic data transmission and it is generally easier to design such networks. Finally, wireless networks are cheaper comparing to traditional wired solutions since they do not require any excavation (CAPEX reduction).

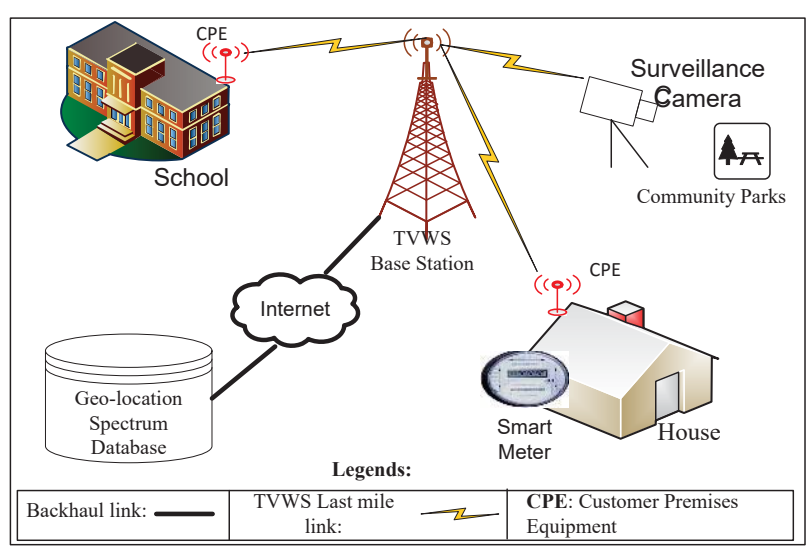

\section{Figure 1: A typical Modern Township with TWWSN coverage}

Thus, let us present the concept of TVWSN which will be analysed in the context of Mankweng Township, but can be straightforwardly adapted to any other developing region. For this region we have identified three essential services, which can be delivered by means of TVWNS. These are e-Learning facilities for schools, e-Surveillance to public centres, and smart metering from homes for municipal billing purposes. Proposed envisioned Modern Township in developing areas is depicted in Figure 1, where a TVWS base station can be shared with existing cellular or municipality masts, or a completely new site can be erected. The customer premises equipment (CPE) communicates directly with the TVWS base station through the TVWS wireless link. At each CPE is then connected to a $\mathrm{Wi}-\mathrm{Fi}$ access point for Internet distribution, and for e-Surveillance, a CPE is directly connected to the surveillance camera. Mankweng Township is only limited to providing Internet connectivity to schools, and other eServices (shown in Figure 1) are possible applications towards modern township. It is important to note that this concept can be easily modified in order to consider other services. As the key concept has been presented, in what follows we will discuss three enablers that are crucial from the perspective of practical deployment of TVWSN in developing areas.

\section{Technical, Legal and Economical Enablers}

The development of the ICT infrastructure and delivery of broadband Internet connectivity to a wide society is an effective way for reducing the development gap between countries and societies [13]. Let us however look at this concept from three perspectives - technological, legal and economical - which we consider as the pillars of reliable community development, as shown in Figure 2. In all cases it is important to analyse the benefits from experiences from the developed nations. In what follows we will prove that existing technological, legal and economic solutions are mature enough to be applied successively for TVWSN deployment in developing regions.

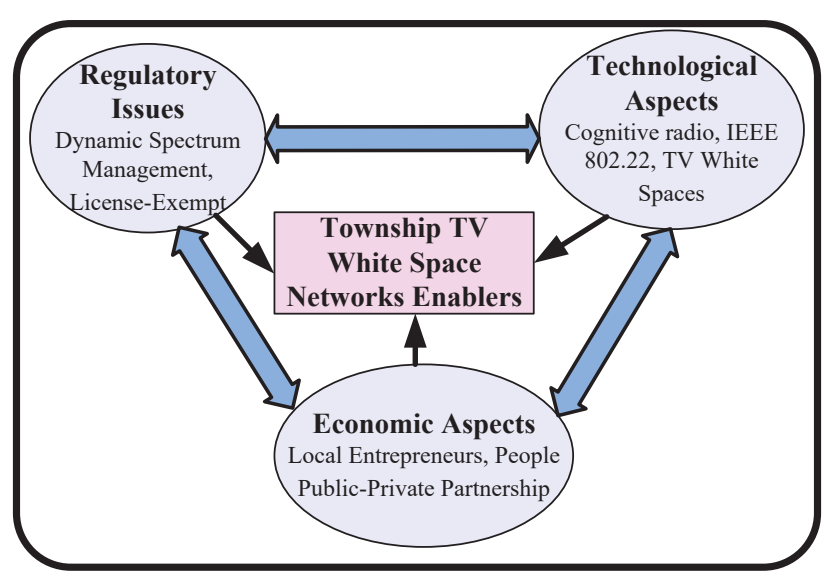

Figure 2: Three pillars of reliable community TVWSN deployment

\subsection{Regulatory Issues - the first pillar}

Focusing first on the technological aspects, one can assume that modern countries suffer from the high scarcity of the available radio frequency (RF) spectrum although its effective utilization is very poor [14]. Thus, advanced and sophisticated technological solutions have been proposed both in North America and Europe to 
allow for opportunistic and flexible utilization of RF spectrum. These can be collected under the umbrella of cognitive radio (CR). Although pure CR concept is still on its research phase, it is worth mentioning the important steps towards its practical implementation.

Standard efforts towards the implementation of CR systems include the IEEE 802.22 which is a wireless regional area network (WRAN), whose amendment is on the final preparation stage. Other efforts are found in the documents with the requirements for the so-called white space devices [14], the family of standards for cognitive radio IEEE 1900.x [16], and the recent decision on assigning the bandwidth from 470 to $490 \mathrm{MHz}$ for dynamic spectrum access solutions in the United Kingdom by the Office of Communications (Ofcom) [17]. These exemplary standards and regulatory documents can be treated as legal basis for the deployment of TVWSN in the nearest future even in developed countries (like South Africa).

As the legal solutions exist and can be applied easily, let us analyse the problem of opportunistic spectrum usage from different perspective. One can claim that many African regions do not suffer from the spectrum scarcity due to lack of telecommunication infrastructure. Thus, potentially there is no need for application of such mechanisms, and spectrum could be assigned in traditional, static way. While this is true, this problem has to be analysed from the long term perspective, especially taking into account the rapidity of the countries' development. Thus, the authors of this work suggest gaining from the experience of other countries and working on such solutions that will allow for easy, cheap and fast deployment of telecommunication infrastructure, and at the same time will guarantee that the current problems of already developed countries will never come to life in Africa ${ }^{\dagger}$. Application of such a solution could indeed reduce the widening gap in the ICT area in developing regions.

However, the presence of legal solutions is just one of many necessary conditions for enabling the ICT network deployment. Therefore, let us discuss the technological aspects from the perspective of developing countries in the next subsection.

\subsection{Technological Aspects - the second pillar}

Lack of fixed-line ICT infrastructure in rural and township areas coupled with recent advancements in wireless communications technology are among the reasons why wireless networks have become the most

\footnotetext{
$\dagger$ It is worth mentioning that analogous situation took place in Poland, the national country of the third author, where due to historical reasons decision on the adoption of MPEG2 or MPEG4 was made much later than in the west Europe. In consequence, Poland had newer standard earlier than many other west countries.
}

inexpensive and preferred solution to address broadband connectivity in underserved area [14]. Despite claims of $100 \%$ cellular network coverage in South Africa, broadband access in rural and township areas remains a challenge. This is partly due to low average revenue per user (ARPU) in rural areas [18] and the high spectrum license fees which constitutes a barrier for new players to enter into the market [19]. While Wi-Fi is capable of providing low-cost broadband connectivity, it is limited to indoor or short range coverage due to its high operating frequency bands. Thus, the most preferred wireless communications solution for rural and township areas should operate in RF spectrum below the $1 \mathrm{GHz}$ band (for greater coverage) and be license-exempted or at low spectrum license fee.

Recent digital migration of television broadcast has freed-up large blocks of RF spectrum in the $470-790$ $\mathrm{MHz}$ band, and this spectrum promises to provide low cost broadband connectivity [20]. Thus, taking into account the above considerations, one of the promising technologies for application in South Africa for delivering broadband connectivity in rural and township areas is the deployment of TVWSNs. Such an alternative has been already considered by international companies, such as Microsoft and Google, which led some measurements campaigns for TVWSN communications [21]. Furthermore, various works have been carried out to adapt the existing guidelines for the devices operating in white spaces to the African situation, such as in [20].

The TVWS pilot project has been deployed in Mankweng Township and the surrounding villages with special focus to selected secondary schools since 2014 [20]. As shown in Figure 3 Limpopo TVWSN connects five secondary schools, of which four of these schools are in rural villages and one school is in the township. This proof-of-concept experiment shows the benefits of the TVWSN application for community development; it can be then treated as technical enabler, the second pillar needed for achieving this goal. It will be analysed in more detailed way in the following sections.

\subsection{Economical Aspects - the third pillar}

Focusing only on the technical and legal aspects will not succeed in the long term perspective. Thus, the overall economic analysis of the proposed solutions shall be the third pillar of the way for country development through broadband Internet connectivity. As the concept of infrastructure deployment and network development relates various groups of the society we propose the People Public-Private Partnership (P4) model as the key economical solution. The P4 model will ensure community participation in the township projects and is contemporarily widely used as a promising solution for development of given region [22]. Involving the local community makes the community to have some sense of ownership to the network, thereby reducing the possibility of vandalism and mature project failures. Thus, the issues 


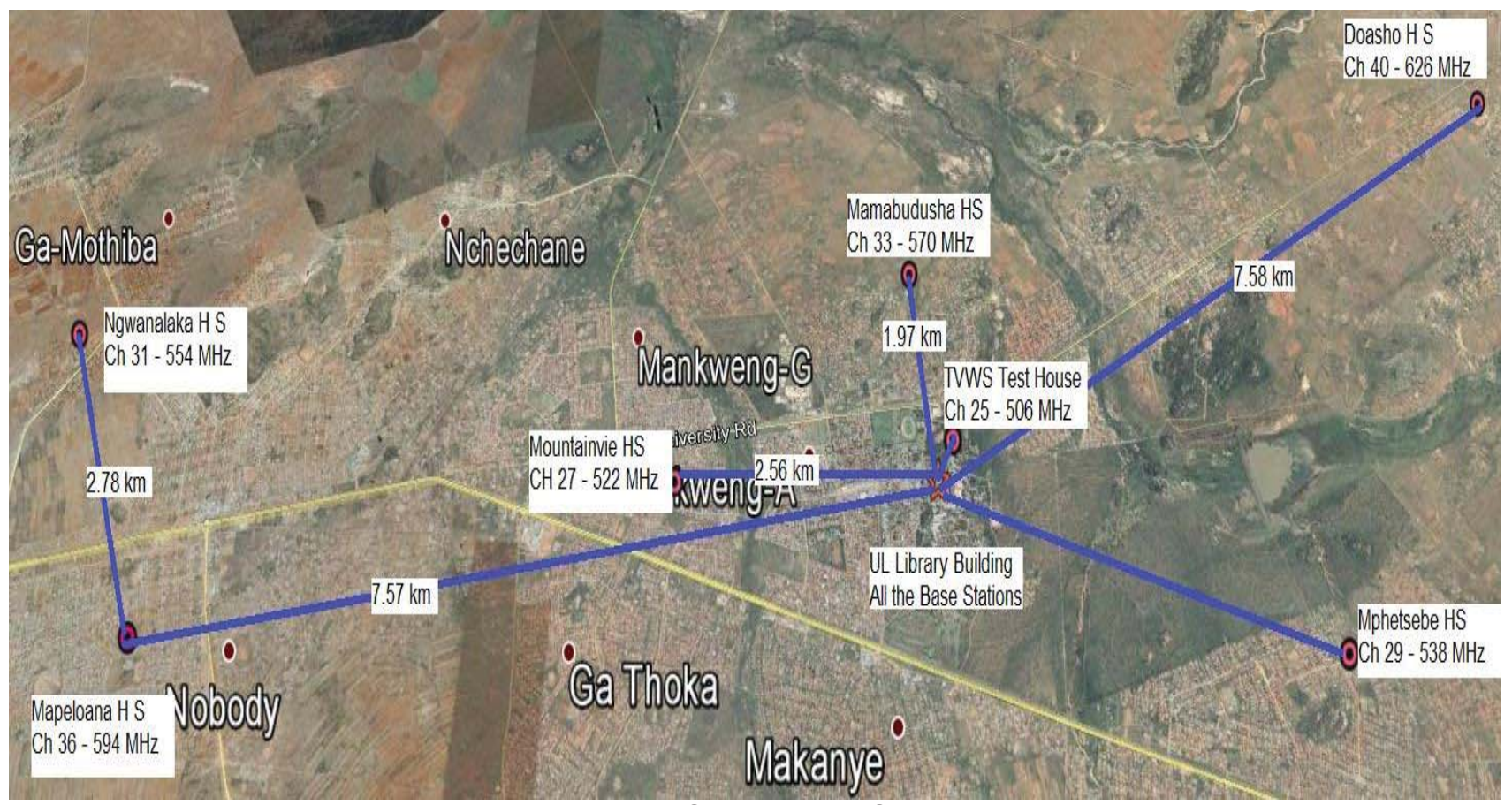

Figure 3: Limpopo TVWSN Topology Showing all sites [20]

of ownership and management have to be split according to the $\mathrm{P} 4$ model.

Our motivation for considering the P4 model as a tool enabling efficient deployment of TVWSN in developing countries bases on the following assumption, typical for P4 model. The mutual benefits will be (or better should be) maximized if there will exist a strict cooperation between local societies (people, social organizations, associations etc.), local market (companies, firms) and national players (like regulators). The main concept of such synergy is illustrated in generic Figure 4 [27]. The role of the public sector would be mainly in creating legal,

\section{Partnership model}

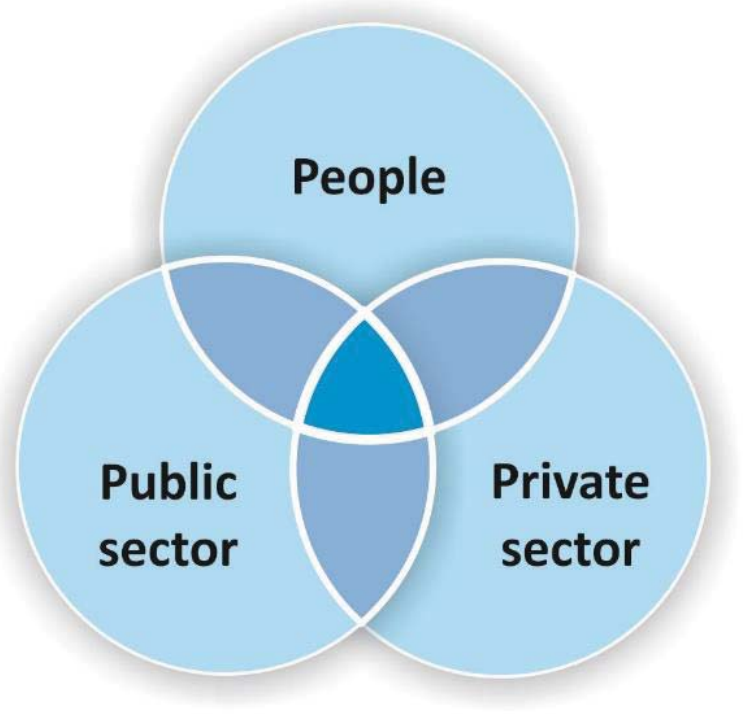

Figure 4: Generic illustration of the P model financial and economic opportunities for realization of the agreed target (in our case, deployment and utilization of TVWSN). Similarly, private sector will be mainly responsible for practical realization of the target, meaning implementation of the new technologies, maximization of the economic benefits, development of the investment plans etc. Finally, the role of the local communities (or more broadly - people) cannot be underestimated. As the end users and key participants of the country development process, they can be responsible for identification of the real needs and expected services, and as such they should be included in the developing process.

As we claim that the utilization of the TVWSN technology can be one of the technical enablers in the process of modernizing African Townships, let us now project the generic $\mathrm{P} 4$ model to the case considered in this work. In such a model, national and local governments will co-invest for TVWSN to provide broadband access in the schools, health centres, and e-Government. Appropriate legal and economic regulation at the national and local levels should be created stimulating the private sector for investments. If possible, dedicated funding programs could be offered for interested stakeholders. Also other specially tailored initiatives shall be started in order to incentive key and new ICT market players to identify fresh markets for their commercial activity. In consequence, such co-investments will encourage the private sector, including small and medium enterprises and village entrepreneurs to enter into the ICT market by providing specialized Internet services within their townships. We believe that the P4 model is also suitable for building wireless community networks for townships and rural communities. Detailed investment plans can be created as community networks are mainly made for 
sharing the information among the community members and the network can be easily expanded as the community grows. This process will be observed in the developing countries as it happened already in other places of the world.

Finally, we think that the role of the people sector should be emphasized, as the local community or even the broad society can significantly influence the TVWSN deployment process. It can be done by defining the real needs and expectations of the local and national communities, establishing associations for monitoring the whole process and providing feedback to the market.

Having in mind that there are already some legal regulations available, as well as the technology seems to be mature enough for practical applications, we believe that the P4 model can be treated as the third, economic pillar for practical TVWSN deployment.

\subsection{Scenario for P4 Model Implementation}

In order to address Internet connections in rural and remote areas in the developing regions, a blend of $\mathrm{P} 4$ and Public-Private Partnership (PPP) models are encouraged. For instance, providing Internet connection to schools, health centres, rural government centres, and rural business centres might require a formal agreement which can be achieved through the PPP model. On the other hand, P4 model might be suitable for connecting the households within the communities.

Now, let us analyse the proposed P4 model as the four step process adopted from [23], where four consecutive phases of its implementation are shown (see Figure 5).

Phase 1: Identification of social and economic targets by the municipality - at this phase, the social and economic targets for the community broadband networks are identified by stakeholders. The main aim of this phase is to identify shared and competing goals by stakeholders as well as matching of crucial policy issues [24]. It is during this phase where stakeholders, especially public and private, take into consideration the potential demand and supply for services to be offered by the planned network. This includes the number of government centres, health centres, schools, businesses and community members to be connected by the network.

Phase 2: Identification and matching of core resources and competences - during this phase stakeholders will be matching different strategic visions with key resources and competences. It is also important to identify possible local community entrepreneurs or champions who will be involved in the project at this phase. One of the common strategic visions is to integrate a public utility with an entrepreneurial attitude approach for deploying community broadband network [23]. At this phase, public-private collaboration is built in order to transform the strategic vision into cooperation where management of funds and risks are shared.

Phase 3: TVWS network deployment - phase 3 involves stakeholders at different level uses their vision, mission and competences to deploy the network. Depending on the choice of PPP model adopted, each stakeholder's involvement will differ based on the contributions to the funding, adopted business model, and the choice of technology used to build the network. The choice of technological standard will depend on the maturity of such standard as well as the available funding to the project.

Phase 4: Provision of broadband services - at this phase, multiple broadband services and applications are provided to the users by the TVWS network. It is at this stage that local community members and entrepreneurs are encouraged to develop local content to share or upload to the network. The broadband market for the community can also be driven by emerging or well established WISPs who will ensure that the community have access to

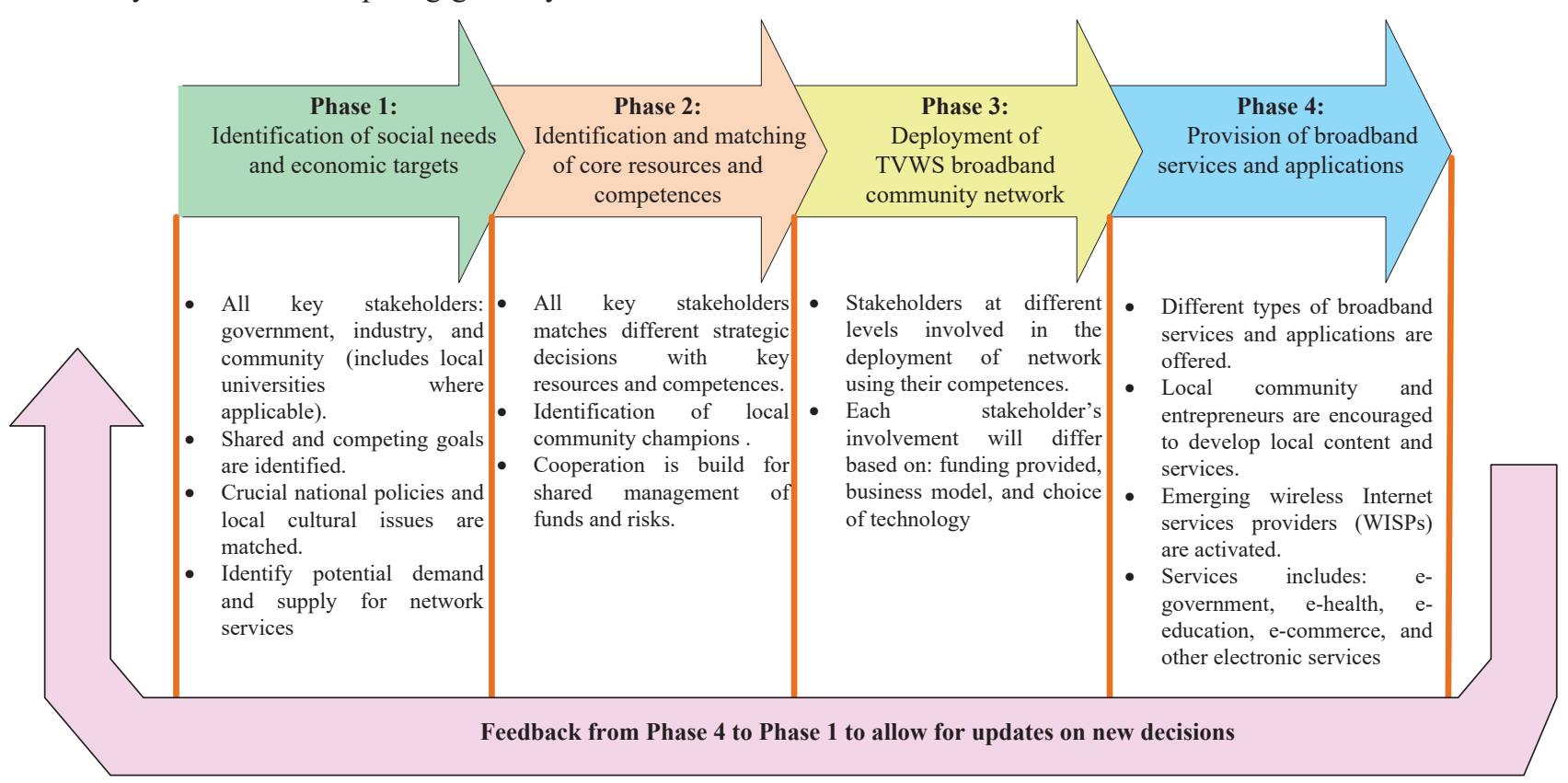

Figure 5: P4 model for Township TVWS Network deployment 
reliable and high speed Internet connection which will in turn address the digital divide gap in most rural areas.

A good example of P4 model is the Village Operator model developed by the CSIR Meraka where a local community entrepreneur is trained to be responsible of operating, promoting and expanding the broadband connectivity in his community [25]. Through this model, the government funds the cost of building and sharing broadband connectivity using mesh networking principles to expand network coverage within the local community at the lowest cost. Once the initial investments are made to build the backhaul link and point of Internet presence, the Village Operator will be responsible to expand the network to the households within the same community. These Village Operators can be the small WISPs using the TVWS to provide Internet access to the hard-to-reach and rural households.

In addition to the Village Operator concept, we propose the living lab model whereby municipalities will partner with the local Village Operators, nearest academic institutions and the private sector to form the P4. By using PPP models for providing broadband access, the municipality can take a lead to such partnerships since their main objectives is to provide broadband access to the community. In such P4 models, it is important to enter into some form of formal contractual agreement especially between the municipality and private sector since they are expected to be the main funders of these initiatives. Depending on the availability of local Village Operators, contractual agreements may last for a minimum of 5 years up-to 20 years. After the end of the agreement period, the partners may agree to reduce, expand or modify the implementation of the project. The same operator can also be responsible for operating and maintaining the local GSDB to ensure no interference is caused to the primary TV band services. The P4 approach has the potential to generate more jobs and to develop necessary skills within the communities.

\section{TVWSN for E-Community}

The previous section demonstrated that there exist technical, legal and economic instruments that can be applied for practical deployment of TVWSNs. Thus, let us now discuss the profits achieved by the whole community through deployment of the TVWSN. We will base on the specific use-cases, i.e. the TVWSN experiments conducted in Mankweng Township under the framework of TVWS pilot in the Limpopo Province. Application of the TVWSN for these exemplary situations should be treated as a way for building the knowledge economy, safety guarantee for society and as an incentive to implementation of innovative solutions for smart cities and towns.

\subsection{E-Learning facilities for rural regions}

The goal of Limpopo TVWS pilot was to deliver access to broadband Internet to the students and teachers. The deployed TVWSN connected 5 schools, as shown in Figure 3 with the offered average backhaul throughput of 7.21 Mbps per radio link [26]. The transmit power of each device was set to $20 \mathrm{dBm}$ according to local agreements.

Among the student population, Grade 8 to 11 were selected using simple random sampling techniques. The student sampling frame of 2979 was compiled from lists provided by the 3 sampled schools (Mamabudusha, Doasho and Mountainview High Schools), from which a decision was made to take a $20 \%$ sample, representing 600 elements, for questionnaire survey. Similarly, a sampling frame of 124 educators was compiled from lists provided by the three schools; and, a total of 24 educators were selected through simple random sampling techniques for survey. Separate questionnaires were used for students and educators. The questionnaires covered a wide range of issues inclusive of the users' confidence in their technological abilities and skills, which is the focus of this article, to use TV White Space for learning and teaching. The questionnaires were loaded into android phones using the online data collection application, Open Data Kit (ODK). The UL Computer Science final year students were employed to administer the ODK-based questionnaires.

Based on the questionnaires collected of the experiences of the participants, most of the respondents (around 80\%) expressed that digital literacy is of highest importance [21]. Most of the respondents were also highly satisfied that they could easily access the word-wide resources. It means that delivering of facilities offered by the TVWSN is highly expected by the community. Students and teachers possessed the practical means for offline and online multimedia delivering and sharing, for circulation of important information and for accessing world-wide resources. As the conducted experiments focuses only on delivering Internet access to township areas, one important question that arose is to check if the e-Learning services could be delivered to the community by means of TVWSN.

Let us notice that by application of flexible spectrum usage the current needs for throughput (e.g. bidirectional video transmission) can be guaranteed by simply assigning more spectrum for this purpose at certain time and location. Such an observation together with the fact of Variable Bit Rates required for MPEG-4 transmission creates an opportunity for adaptive service delivery to the user. For an established single connection of $10 \mathrm{Mbps}$ third level of baseline, extended and main profile can be achieved (with the maximum resolution of $720 \times 576$ with the frame rate of 25.0). Application of TVWSN will optimize the energy consumption and improve the effective usage of spectrum - once the higher throughput is needed more spectrum or more advanced transmission techniques will be applied. 
It is important to note that the cost of deploying a wireless network is much less comparing to the cost of wired network. Moreover, by application of TV-band for radio communication, relatively high distances of signal delivery can be achieved compared to e.g. free Wi-Fi band. Let us consider the following example - for a given transmit power, distance and antenna gains, the path loss of such link will be approximately $3^{\zeta}$ times higher for 2.4 $\mathrm{GHz}$ centre frequency comparing to the $800 \mathrm{MHz}$ one, where $\zeta$ stands for attenuation factor. It means that the transmit power can be reduced $3^{5}$ times to achieve the same range just by reducing the carrier frequency.

\subsection{E-Surveillance through TVWSN}

A natural application of video-transmission through the TVWSN is the remote monitoring or e-Surveillance. As the crime problems are of highest importance in every country, and particularly in the regions where economical changes influences wide communities, safety guarantee to the citizens is crucial. As the presence of municipal services is necessary, the effectiveness of their work can be improved by delivering them the tools for remote monitoring of particularly dangerous areas. Omitting intentionally the privacy issues, which have to be also considered, the analysis of the applicability of the TVWSN for such a purpose will be similar as for eLearning scenario. However, probably the scale problem could be the key issue here, since the number of video streams will be relatively much greater than for the eLearning case. On the other hand the communication will be mainly one-directional in this case what eases the system design. Again, the flexibility of TVWSN allows for effective deployment of such a network for surveillance purposes. Based on the experiments conducted in Mankweng Township one can deduce that such an appropriately designed network can be applied also in this scenario.

\subsection{Smart metering for water resources}

One of the key problems in African countries is the need for long-distance travelling by collectors in order to check the gauges (for example water consumption). Automation of this procedure will provide cost savings for the companies, and will guarantee timely and accurate delivering of the current meter readings. Application of TVWSN for these purposes seems to be fast and easy way for achieving this goal. Let us check the technical possibility of the deployed TVWSN in Mankweng Township for this scenario. In order to estimate the generated traffic, let us assume that each household is equipped with one gauge, and the meter readings are checked every hour. In order to send the measured values accurately each gauge needs to transmit its identity (arbitrarily set to 32 bits) and the value itself (again 32 bits). Having in mind the number of habitants in the considered Mankweng Township (33,738 of habitants in
2011 year, what results in the density of 2,800 people per $\mathrm{km}^{2}$ ) the total average traffic that has to be served is approximately equal to64 $\cdot 2800 \frac{\mathrm{bph}}{\mathrm{km}^{2}} \approx 50 \frac{\mathrm{bps}}{\mathrm{km}^{2}}$. Please note that this value can be reduced by the average number of persons per one household and by the reduction of meter reading collection frequency (e.g., once per day). Finally, the application of TVWSN for smart metering seems to be a very promising solution due to its low cost of deployment and high flexibility. Please note that once the infrastructure for water-gauges remote metering is built it can be adopted also to other services, such as energy consumption metering.

\subsection{Social networking}

The great role that the so-called social networks play in the developed countries is a vivid subject of sociological investigations for many years. New view on the human relations due to the practical implementation of concept of being "in" every-time and every-where changed significantly the traditional way in almost every aspect of life. This situation will also happen in the steeply rising communities, such as those in SADC regions. Clearly, such a situation creates both: great opportunities for community development on the one hand side, and big threats on the other. Having this in mind, application of TVWSN in developing countries can be treated as the tool for broadband internet connectivity allowing also spreading of the social networks. From technological point of view, active participation in the social networks assumes periodic (regular) uploading of short posts (e.g. like on Twitter, or leading own blogs), photos (e.g. Facebook, Instagram), or short videos (like in Youtube). Thus, the amount of data (per one user) which has to be transferred using wireless network will be much less than in a case of e-surveillance or online video streaming. The main problem will appear in the densely populated regions, where many social network members would like to update their profile. However, having in mind the amount of white spaces identified in the SADC regions, as well as various ways for network densification, this problem shall be easily solved.

\subsection{Broadband internet access for e-community}

The above example with social networks should be in fact treated as the very specific case of e-community. Availability of the network connection "every time and everywhere" could create great opportunities for society development and its transformation (in positive sense) into so-called e-society. Legal and technical opportunities delivered to the end users will incentive various social groups or single persons for establishing new start-ups. Local companies can provide their offer to more distant customers, and offices can provide facilities for electronic management of various issues. Clearly, it is well known 
that all of the abovementioned aspects will happen as only broadband internet connectivity will be guaranteed. As it is true, we do claim that deployment of TVWSN can be treated as the key tool for fast and relatively cheap delivering broadband connectivity in African countries, especially in rural areas where the distances between the villages are high. The experiments in Mankweng Township proved that it is practically possible and effective to deploy TVWSN even if the distances between the network nodes are large. It can be than envisaged that TVWSN-based broadband internet access will be the stimulus for e-community development.

\subsection{P4 discussion for Mankweng Township}

As the technological aspects have been already discussed in other papers, e.g. in [20], let us briefly discuss the ways on how the P4 model can be applied. First, let us observe that the appropriate framework for realization of such concept has been already provided to the community by some of the countries in Southern African Developing Community (SADC) regions (please refer to Section 2. II). Second, the need for delivering of various services and facilities through easy and reliable Internet access has been also proved by the conducted experiments in Mankweng Township - most of the respondents expressed the importance of digital literacy. Also, the fact of the tests carried by Microsoft in some sense proves the potential interest of private companies in this activity. Thus, in the $\mathrm{P} 4$ model the missing nexus is the existence of private companies (e.g. village or town operators through the local government) that will deliver the above mentioned services to the users. Such a movement can be supported by local government by creating dedicated economical areas or providing dedicated programs for interested commercial bodies in favour of the communities.

\section{Conclusions}

In this work we have discussed the possibilities of township area development using Mankweng Township as a case. ICT infrastructure and the delivery of broadband Internet connectivity were discussed using three perspectives namely, regulatory issues, technological and economical aspects. This paper further demonstrated that the use of TVWSN in townships and rural settings is beneficial and can accelerate development. Additionally, ways in which to apply the P4 model were also discussed in the paper. The paper then concludes that in order to achieve community development which will improve quality of life in the townships and rural areas, the use of TVWSN based on the P4 model is highly beneficial.

Further work would include the realization or practical implementation of the proposed concept in a township or community in developing or developed community. Such might include the need for regulations to enable the facilitation of P4 model by engaging the key stakeholders

\section{Acknowledgment}

A. Kliks has been funded by the Polish Ministry of Science and Higher Education for the status activity supporting development of young scientists and doctoral students in year 2015 (DS/08/81/0155/15) and 2016 (DS/08/81/0165/16). The first and second authors acknowledge the financial support by the South African Department of Science and Technology, University of Limpopo and Council for Scientific and Industrial Research.

\section{References}

[1] H. Martadwiprani and D. Rahmawati, "Economic development as community resilience enhancement in Minapolis coastal settlement," Procedia-Social Behavioral Sciences, vol. 135, pp. 106-111, 2014.

[2] G. Lizarralde, K. Chmutina, L. Bosher, and A. Dainty, "Sustainability and resilience in the built environment: the challenges of establishing a turquoise agenda in the UK," Sustainable Cities and Society, vol. 15, pp. 96-104, 2015.

[3] Z. Huang, Y. D. Wei, C. He, and H. Li, "Urban land expansion under economic transition in China: a multilevel modeling analysis," Habitat International, vol. 47, pp. 69-82, 2015.

[4] P. Harrison and A. Todes, "Spatial transformations on a "loosening state": South Africa in a comparative perspective," Geoforum, vol. 61, pp. 148-162, 2015.

[5] L. Criquei, "Infrastructure urbanism: roadmaps for servicing unplanned urbanisation in emerging cities," Habitat International, vol. 47, pp. 93-102, 2015.

[6] F. Markham and B. Doran, "Equity, discrimination and remote policy: investigating the centralization of remote service delivery in the Northern territory," Applied Geography, vol. 58, pp. 105-115, 2015.

[7] T. M. Ramoroka, M. T. Masonta, A. Kliks, "TV White Space Networks Deployment: A Case Study of Mankweng Township in South Africa", 7th EAI International Conference on e-Infrastructure and e-Services for Developing Countries, | Cotonou, Benin, December 15-16, 2015.

[8] L. Criqui, "Infrastructure urbanism: roadmaps for servicing unplanned urbanisation in emerging cities", Habitat International, vol. 47, 2015, pp. 93-102.

[9] F. Markham and B. Doran, "Equity, discrimination and remote policy: investigating the centralization of remote service delivery in the Northern territory", Applied Geography, vol. 58, 2015, pp. 105-115.

[10] National Planning Commission, National Development Plan 2013: Our Future-Make it Work. Government Printers: Pretoria, South Africa, 2012.

[11] Department of Science and Technology and Council for Scientific and Industrial Research, Towards Digital Advantage: Road mapping South Africa's ICT RDI Future. Government Printers: Pretoria, South Africa, 2013, 
[12] Department of Communication, South Africa Connect: Creating Opportunities, Ensuring Inclusion. Government Printers: Pretoria, South Africa, 2013.

[13] A. Fehske, G. Fettweis, J. Malmodin, and G. Biczok, "The Global Footprint of Mobile Communications: The Ecological and Economic Perspective," IEEE Comm. Mag., vol. 49, no. 8, pp. 55-62, 2011.

[14] T. Olwal, M. T. Masonta, L. Mfupe, and M. Mzyece, "Broadband ICT policies in Southern Africa: Initiatives and dynamic spectrum regulation," in IST-Africa Conference, Kenya, 29-31 May 2013.

[15] ETSI, "White Space Devices (WSD); Wireless access systems operating in the $470 \mathrm{MHz}$ to $790 \mathrm{MHz} \mathrm{TV}$ frequency band," EN 301598 V1.0.9 (2014-02), 2014.

[16] IEEE DySPAN, "IEEE DySPAN Standards Committee (DySPAN-SC)." 2015.

[17] Ofcom, "Implementing TV white spaces." 2015, [Online] Available $\quad$ from: http://stakeholders. ofcom.org.uk/binaries/consultations/white-spacecoexistence/statement/tvws-statement.pdf, accessed: 19 April 2016.

[18] A. Fehske, G. Fettweis, J. Malmodin \& G. Biczok, "The Global Footprint of Mobile Communications: The Ecological and Economic Perspective," IEEE Comm. Mag., vol. 49, no. 8, pp. 55-62, 2011.

[19] H. Gruber, "Spectrum limits and competition in mobile markets: the role of licence fees," Telecommunications Policy, vol. 25, pp. 59-70, 2001.

[20] M. T. Masonta, A. Kliks, and M. Mzyece, "Framework for TV White Space Spectrum Access in Southern African Development Community (SADC)," in 24th IEEE PIMRC, London, 2013.

[21] M. T. Masonta, T. M. Ramoroka, and A. A. Lysko, "Using TV White Spaces and e-Learning in South African Rural Schools," in IST Africa, Malawi, 2015.

[22] S. Gumbo, H. Thinyane, M. Thinyane, A. Terzoli, and S. Hansen, "Living lab methodology as an approach to innovation in ICT4D: the Siyakhula living lab experience," in IST Africa, 2013.

[23] A. Nucciarelli,B. M. Sadowski, and P. O. Achard, Emerging models of public-private interplay for European broadband access: evidence from the Netherlands and Italy. Telecommunications-Policy, 34, pp. 513-527, 2010

[24] M. Mandviwalla, A. Jain, J. Fesenmaier, J. Smith, P. Weinberg and G. Meyers. Municipal broadband wireless networks. Communications of the ACM, vol. 51, no. 2, pp. $72-80,2008$

[25] M. Herselman, U. Du Buisson, M. Marais and M. PitseBoshomane, Outcome mapping as methodology to monitor and evaluate community informatics projects: a case study. Prato CIRN-DIAC Community Informatics Conference, , Italy, 27-29 October 2010.

[26] M. T. Masonta, L. Kola, A. A. Lysko, L. Pieterse, and V. Mthulisi, "Network performance analysis of the Limpopo TV white space (TVWS) trial network," in IEEE Africon, Sept. 2015.

[27] CTO, "Management of USAFs: Funding Streams", Published on May 11, 2011, CTO Workshop, Cameroon, available online: http://www.slideshare.net/CTOResearch/management-of-usafs-module-six, accessed: 16 April 2016. 